\title{
TEATRO COMO ESPEJO DEL TEATRO
}

\section{Urszula ASZYK, José ROMERA CASTILLO, Karolina KUMOR y Kamil SERUGA (eds.)}

(Madrid: Verbum, 2017, 287 págs.)

Teatro como espejo del teatro es un volumen que publican conjuntamente el Centro de Investigación de Semiótica, Literaria y Teatral (SELITEN@T), dirigido por el catedrático José Romera Castillo (UNED; Madrid) y el Instituto de Estudios Ibéricos e Iberoamericanos de la Universidad de Varsovia, dirigido por la catedrática Urszula Aszyk, con el patrocinio de la Asociación Internacional de Teatro del siglo XXI (AITS21).

Este es el tercer título de una serie denominada "Teatro español como objeto de estudios" (2015), fruto de las investigaciones llevadas a cabo por el citado Instituto de Estudios Ibéricos e Iberoamericanos. El trabajo compendia dieciocho artículos que examinan la variedad metateatral en los textos de determinados autores y autoras, desde el Siglo de Oro hasta la actualidad (a lo que se dedican las dos primeras partes del libro), así como en las puestas en escena de profesionales de la dirección teatral, la escenografía, la coreografía o la interpretación, (a lo que se dedica la tercera parte). El volumen lo abren José Romera Castillo y Urszula Aszyk, quienes, en sus respectivas presentaciones, ofrecen exhaustiva cuenta de la gran trayectoria que les avala tanto a ellos mismos como a sus respectivos equipos.

Sobre el Siglo de Oro escriben Beata Baczynska y María Luisa Lobato, en concreto, sobre los géneros menores. Mientras que Lobato se dedica a la metateatralidad de las jácaras —especialmente, de Quiñones de 
Benavente, precursor de este género-, destinada a provocar la participación del público en la representación, Baczynska se ocupa de Calderón de la Barca, demostrando que el theatrum mundi no solo está presente en La vida es sueño, sino en piezas como la loa La segunda esposa, el auto $L a$ protestación de la fe y la mojiganga Las visiones de la muerte, mediante la introducción de fiestas sacramentales dentro de dichas obras. Por su parte, Fátima López López Pielow recoge el hallazgo de la metáfora calderoniana para descubrírnosla en El público y Así que pasen cinco años, de Lorca, y Himmelweg, de Juan Mayorga, esclareciendo, así, una tendencia que se observa a lo largo de la historia del metateatro español.

La mencionada López López Pielow inaugura la sección dedicada a la Edad de Plata, de la que también se ocupan Eszter Katona, Urszula Aszyk - con un elemento en común en las tres: el teatro irrepresentable o imposible de Lorca: El público, Así que pasen cinco años y Comedia sin título- y Katarzyna Górna, quien disecciona la estructura metateatral de mise en abyme de Judit, de Azorín, donde la transgresión de los diferentes niveles de ficción persigue el cuestionamiento del concepto de identidad y el desconcierto en la persona receptora.

Eszter Katona, por su parte, expone algunas de las obras más representativas de Lorca - Teatro de almas, El maleficio de la mariposa, El Retablillo de don Cristóbal, Comedia sin título, La zapatera prodigiosacomo un extenso muestrario de estrategias metateatrales donde se encuentran la autorreferencialidad, la mise en abyme o el teatro dentro del teatro, que aparecen tanto en los prólogos como en el cuerpo de las propias obras.

Lorca también es estudiado por Urszula Aszyk quien, además de El público y Comedia sin título, considera los procedimientos autorreferenciales de El teatro en soledad, de Gómez de la Serna, Los cuernos de don Friolera, de Valle-Inclán, El señor de Pigmalión, de Jacinto Grau, y Comedia del arte, de Azorín, íntimamente ligados al debate por la renovación del teatro, en las primeras décadas del siglo xx, contexto en el que se producen estas piezas.

Del mismo modo que Lorca, Alfonso Sastre se sirve de la metateatralidad para reflexionar sobre su propio quehacer dramatúrgico, pero además, como explica Miguel Carrera Garrido — quien abre el apartado del metateatro en la Contemporaneidad - en su análisis de la tetralogía de Los crímenes extraños, Sastre pretende infundir la duda acerca de la idea 
de la obra acabada, invocando la complicidad de la persona receptora, para lo que se sirve de estrategias autorreflexivas, como la autoconciencia de los personajes y el intervencionismo constante del dramaturgo.

La figura del autor vuelve asimismo a hacerse presente en sus propios textos, en las obras de Jerónimo López Mozo que analiza Karolina Kumor: El engaño a los ojos, El olvido está lleno de memoria, Madrid-París y $A$ telón corrido. Partiendo de los homenajes a otros dramaturgos que López Mozo realiza mediante las referencias teatrales y el teatro dentro del teatro, Kumor nos descubre la verdadera intención del autor, que es realizar una dramatización de la historia de la escena española dentro de la que reivindicar su sitio como integrante del teatro de vanguardia.

Homenajes a la tradición teatral española también ha vislumbrado Katarzyna Wojtysiak-Wawrzyniak al analizar Pepe el romano, El descenso de Lenin o ¡Santiago (de Cuba) y cierra España!, de Ernesto Caballero, que muestran deudas con Calderón, Lorca y Valle-Inclán. La huella intertextual, así, se convierte en metateatro por las referencias a la propia historia del teatro. Este teatro sobre el teatro deja paso a la dimensión más filosófica y existencial del metateatro, como adivina Natalia Szejko cuando aborda el análisis de Jindama, de Alfonso Vallejo. La multiplicidad de personajes que surgen a partir de la estructura del teatro dentro del teatro desemboca en un profundo desencanto con la realidad y la existencia humana, ambas, volátiles e inasibles.

Sobre consideraciones existenciales, ser y parecer, la ilusión y la realidad también versa el metateatro - en forma de teatro dentro del teatro, ficciones subjetivas, improvisaciones y autorreferencialidad o teatro sobre teatro- de Manuel Veiga, que María Falska analiza en Una noche de felicidad y Tormenta de nieve. Similar abanico de procedimientos metateatrales disecciona Kamil Seruga en Viento en las velas, de Llàtzer García, los cuales, además, aparecen imbricados unos en otros para reincidir en la cuestión del replanteamiento de la realidad en nuestra época posmoderna, creadora de ficciones virtuales.

Cierra estas dos partes dedicadas a los textos metateatrales Francisco Gutiérrez Carbajo, quien nos ofrece un rico y complejo panorama del más reciente metateatro en la escena española, tomando como referencia a José Sanchis Sinisterra y su uso de la autorreflexividad, para buscar una forma de reflejar la conciencia humana frente a la figuratividad del realismo. No en vano, Lionel Abel ya dejó establecido que "Metatheatre gives by far 
the stronger sense that the world is a projection of human consciousness"1. Partiendo de este concepto de metateatro, Gutiérrez Carbajo analiza textos de Elena Belmonte, Yolanda Dorado, Juana Escabias, Alfonso Zurro, José Manuel Corredoira, José Moreno Arenas, Miguel Murillo, Alfonso Vallejo, Jerónimo López Mozo, por nombrar algunos. En las citadas piezas, la autoconciencia se manifiesta tanto por el propio autor o autora como por los personajes, estableciendo debates o discusiones entre ambas entidades, así como a través de la autorreferencialidad o la alusión a otros dramaturgos y textos teatrales, con mayor o menor grado de intertextualidad. Texto en el que sintetiza su prólogo a la antología de Varios Autores, La paradoja del dramaturgo (Madrid: Esperpento Ediciones, 2016).

Una de las aportaciones más relevantes de este libro está en el tratamiento de la metateatralidad en la puesta en escena, a lo que se dedica la tercera parte inaugurada por Elzbieta Kunicka, quien reivindica la figura de Cipriano Rivas Cheriff como uno de los artífices de la renovación del teatro español en el primer tercio del siglo xx, junto a Valle-Inclán y Lorca, entre otros. Kunicka establece como signo de esa renovación los proyectos de Rivas Cheriff al frente de su grupo Mirlo Blanco, con obras como Trance, que ponían en práctica su teoría de la marionetización del actor como técnica que le permitiera alejarse del realismo.

Diversos niveles de interpretación actoral para hacer frente a ese papel dentro del papel derivado del teatro dentro del teatro pueden observarse asimismo en los dos montajes que compara Katarzyna Kacprzack: el español La torna de la torna, de Joglars, y el polaco Los expedientes, del grupo Teatro del Octavo Día, que dramatizan sucesos relacionados con la represión política en sus respectivos países, acaecidos tres décadas atrás. Debemos agradecer a esta autora que nos descubra la analogía entre estas dos representaciones que muestran soluciones metateatrales similares para poner en escena problemáticas muy cercanas, aunque alejadas en el espacio.

En cuanto a la escenografía, Karolina Klejewska se sirve del concepto del espacio como flujo y su relación con el espacio autorreferencial que se crea con la inclusión de pantallas dentro de la representación. Ejemplos de esto son las creaciones del director teatral Rodrigo García y el coreógrafo

1 L. Abel (2003). Tragedy and Metatheatre. Essays on Dramatic Form. New York/London: Holmes\&Meyer, pág. 183. 
Juan Domínguez, en las que se ponen en cuestión las realidades creadas por los medios de comunicación.

Una de estas realidades cuestionadas podría ser el capitalismo, representado en las luchas de poder que dramatiza José Martret en M.B.I.G. (McBeth International Group). Guillermo Laín Corona nos hace caer en la cuenta de que, a pesar de la evidente intertextualidad, Martret crea una obra autónoma recontextualizando la original, mediante el procedimiento del teatro dentro del teatro.

La pieza que completa este panorama del metateatro español desde el Siglo de Oro con especial escala en nuestros días la aporta el profesor José Romera Castillo, en un análisis pleno de rigor y novedad, quien incorpora los espectáculos teatrales de los dos últimos años, tomando como referencia la cartelera madrileña. José Romera llama la atención sobre el hecho de que el arte que se cita a sí mismo y, en concreto, el metateatro, persigue una autoevaluación sobre la que poder renovarse. Bajo esta perspectiva, el citado investigador nos descubre producciones protagonizadas por autores, autoras, actores, actrices y compañías de teatro, firmadas por Ernesto Caballero, Beatriz Cabur, Noelia Adánez, José Luis Alonso de Santos, Borja Ortiz de Gondra, Juan Mayorga o Jordi Casanovas, por nombrar algunos ejemplos.

En definitiva, este estudio entronca con una corriente investigadora representada por Ángel Abuín, Alfredo Hermenegildo, Urszula Aszyk, José Luis García Barrientos, Garrot Zambrana o Pilar Jódar Peinado, por citar algunos nombres, que, desde finales del siglo xx y principios del XXI, se ha ocupado del metateatro como una forma alternativa de acercamiento al teatro español, revisando los hitos de la escena española y descubriendo homenajes a otros textos teatrales, así como signos de renovación y autodiagnóstico de la situación de la escena de nuestro país.

Pilar Jódar Peinado Universidad de Salamanca 
